NASA Technical Memorandum 101396

\title{
Sensor Failure Detection for Jet Engines
}

Walter C. Merrill

Lewis Research Center

Cleveland, Ohio

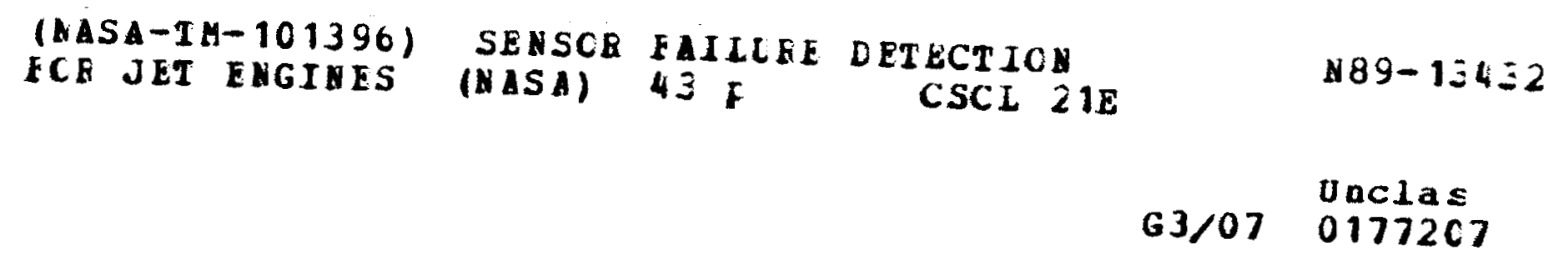

November 1988 


\title{
SENSOR FAILURE DETECTION FOR JET ENGINES
}

\author{
Walter C. Merrill \\ NASA Lewis Research Center, Cleveland, Ohio
}

This chapter surveys the use of analytical redundancy (AR) to improve turbine engine control system reliability. Since 1950, hydromechanical implementations of turbine engine control systems have matured into highly reliable units. However, as shown in Fig. 1, an increase in control complexity has occurred and is expected to continue. This increased complexity has made it difficult to build reliable, low-cost, lightweight hydromechanical controls. On the other hand, microprocessor-based digital electronic technology allows complex control systems to be built with low cost and weight. However, these digital electronic controls do not have the maturity and, therefore, the demonstrated reliability of hydromechanical engine control systems.

Thus, in an effort to improve the overall demonstrated reliability of the digital electronic control system, various redundancy management techniques have been applied to both the total control system and to individual components. One of the least reliable of the control system components is the engine sensor. In particular, a study of fault-tolerant electronic engine controls ${ }^{1}$ shows that sensor redundancy will be required to achieve adequate control system reliability. There are three types of sensor redundancy: direct, analytical, and temporal. Direct, or hardware, redundancy uses multiple sensors to measure the same engine variable. Typically, a voting scheme is used to detect failures. Analytical redundancy uses a reference model of the engine and redundant information in dissimilar sensors to provide an estimate of a measured variable. Estimates and measurements can be used in a variety of ways to detect failures. 
Temporal redundancy uses redundant information in successive samples of the output of a particular sensor to determine failures. Range and rate checks are simple and often used examples of temporal redundancy.

Hardware redundancy is insensitive to failure magnitude since any detectable discrepancy between two like sensors indicates a failure. Thus, hardware redundancy handles hard (out-of-range or large in-range) failures as well as soft (small in-range or drift) failures. Analytically redundant schemes can distinguish failure type and, in fact, can be made sensitive to a particular type, such as soft failures. Range and rate checks are simple and reliable detection methods, but are limited to hard failures. Often range and rate checks are combined with analytical redundant schemes to cover both hard and soft failure types. As shown in Ref. 1, hardware redundancy results in more costly, heavier, less practical, and less reliable systems than do various analytical redundancy strategies. Since cost, weight, and reliability are important drivers in turbine engine control systems design, many researchers have investigated analytical redundancy strategies.

State-of-the-art digital electronic control schemes, such as that for the PW 2037 engine, ${ }^{2}$ make use of a combination of hardware and analytical redundancy to provide adequate system reliability. Here, dual-redundant sensor measurements and a synthesized or estimated measurement are compared to detect sensor failures. This approach is comparable to that used in the aircraft control for the $F 8$ digital fly-by-wire aircraft. 3 In each case a two-step approach is used. First the dual sensors are compared to determine if a discrepancy exists. Then a comparison is made to the estimate to isolate the faulty sensor. Operation continues with the good sensor. Here analytical redundancy allows system operation after both sensors have failed 
to further improve system reliability. Eventually, as AR-based techniques improve, additional reliance on AR strategies would allow single-sensor operation with the resultant savings in cost and weight.

The objective of this chapter is to survey the application of analytical redundancy to the detection, isolation, and accommodation (DIA) of sensor failures for gas turbine engines. This includes those approaches that use software implementations of temporal redundancy combined with analytical redundancy. Hardware redundant strategies are not covered. This survey first reviews the theoretical and application papers which form the technology base of turbine engine analytical redundancy research. Second, the status of important ongoing application efforts is discussed. Also included is a review of the PW2037 engine control system sensor AR strategy. This is the first operational engine to include AR-based strategies. Finally, an analysis of this survey indicates some current technology needs.

I. Analytical Redundancy Technology Base

In this section, papers that document the AR technology base will be reviewed. Seventeen papers are considered. The papers will be reviewed in essentially chronological order. The attributes of each paper, as discussed in this section, are summarized in Table I.

Wallhagen and Arpasi4 presented the first (April 1974) use of sensor AR to improve engine control system reliability. A 385, single-spool, turbojet with two sensed variables and three controlled variables was tested at a sea-level-static condition. The inputs were compressor variable geometry, fuel flow, and exhaust nozzle area. The sensors were a magnetic pickup for rotor speed and a high-response gage transducer for compressor static discharge pressure. Failure detection was accomplished by comparing the 
rate of change of the sensed variables with predetermined limits. Four consecutive out-of-range rates declared a failure. Since each sensor was tested for catastrophic, i.e., hard failure only, isolation is immediate. Failures are accommodated by replacement of the failed sensed value with a synthesized estimate. This synthesized variable is obtained from a tabulation of the synthesized variable as a function of the remaining engine variables. Different tables were stored for steady-state and acceleration conditions. No explicit dynamical relationships were included. The DIA logic was implemented in fixed-point assembly language on a minicomputer. The implementation executed in a 15-ms time frame which allowed real-time interaction with the control. Testing in a sea-level-static test stand compared idle to full-power step responses of rotor speed and thrust. For single failures, steady-state speed was held to within 1 percent of its final value and 92 percent of maximum thrust was achieved. For two sensor failures, steady-state speed was approximately 99 percent of its final unfailed value and thrust was 87 percent of maximum. Time to accelerate, however, had to be increased from 3 to $30 \mathrm{~s}$. Failures were induced at 50 percent power during a transient. Detection was reliable. The system also allows self-healing. An interesting feature of the DIA logic was its ability to learn, on line, all the data necessary to function. In a companion paper, Hrach et al.5 used a real-time nonlinear hybrid computer simulation of a two-spool turbofan, the TF30-P-3 engine, to demonstrate the DIA logic of Ref. 4 over a wide operating range. Four sensed variables: high-pressure rotor speed, high- and low-pressure compressor discharge static pressures, and nozzle total pressure; and five inputs: main fuel flow, nozzle area, afterburner fuel flow, and two compressor stage bleeds 
were considered. Again hard failure detection and isolation were obtained by individual rate checks.

Accommodation was achieved by replacement with averaged synthesized variables which were a function of the remaining good sensors $(1,2$, or 3 ). Synthesized variables were obtained from tabulations. However, the data were now stored as corrected values to allow a wide operating range. Data for the tables were collected at two operating points.

A real-time implementation of this DIA logic was programmed using assembly language in a minicomputer using a frame time of about $0.025 \mathrm{~s}$. Storage requirements include $4 K$ bytes for the $\operatorname{logic}$ and $0.2 K$ bytes for the tables. The logic was tested at five selected operating points (which include the two design points). Acceptable operation with no limit violations and approximately the same thrust was obtained for operation with 1 to 3 of the 4 sensors failed. For afterburning operating of the engine, acceptable control was possible for only a single failure and with a severe rate limit on accelerations. This logic also incorporated learning or adaptive logic.

Ellis (January 1975) studied the use of AR techniques using a nonlinear digital simulation of a two-spool turbofan engine. The engine has five measured variables and two independent controlled variables. The DIA philosophy of this paper centers around estimates of the measured variables. First a multivariable linearized mapping (no explicit model dynamics) of corrected measurements to estimates is found. Since the engine has only two independent controls, it is assumed that only two measurements are required to generate an estimate. Taking unordered pairs of the five measured variables yields ten estimates of each measured variable. A weighted-average estimate is obtained by combining these ten component 
estimates, each weighted by its relative accuracy. Detection and isolation are accomplished by a threshold check on both sides of each weighted average estimate. If a weighted estimate is outside of the threshold corridor then all weighting factors associated with this estimate are set to zero. Weighted estimates are used by the control at all times. Only the weightings change as failures occur. Thresholds for the weighted estimates are obtained from sensor error statistics assuming Gaussian distributions.

The next contribution to this area is documented in four reports $7-10$ by deSilva and Wells. This series of reports applies Bayesian hypothesis testing to the detection of engine sensor failures. The engine studied is a simple turbojet with two outputs, speed and thrust, and one input, fuel flow. A second-order pseudolinear model of the engine was used on a mainframe computer to evaluate detection performance. A pseudolinear model consists of a dynamical, linear state-space structure where individual coefficients within the linear structure vary as a nonlinear function of the state. Bayesian hypothesis testing is implemented by ( 1 ) defining a risk function, and (2) determining from measured data the hypothesis that minimizes this risk. This risk function defines the penalty associated with selecting a false hypothesis. Assuming Gaussian noise statistics, the lowest risk Bayesian hypothesis is also probabilistically most likely given the measured data. A "bank" of Kalman filters, one per hypothesis, uses measured data and an engine model to generate state estimates and filter residuals. The hypothesis associated with the most likely set of residuals, as determined by a likelihood ratio test, is taken as the true hypothesis. The mode of operation associated with this hypothesis (failed speed sensor, no failure, etc.) was assumed true. The approach worked well in simulation studies of this simple case. This work represents the first application of 
analytical redundancy to turbine engines based upon modern control theory. Difficulties with this approach include the requirement of a different Kalman filter for each failure mode hypothesis.

In June 1977 Spang and Corleyll published an application of AR techniques to the quiet, clean, short-haul, experiment engine (QCSEE). This engine has seven measurements: fuel flow, compressor stator angle, fan speed, compressor speed, compressor discharge temperature and pressure, and turbine discharge temperature. Engine controls include fuel flow valve current and compressor stator vane blade torque motor current. In this study an extended Kalman filter approach is used to generate state estimates and residuals. A simplified nonlinear component model that is valid throughout the engine operating envelope and a simplified feedback gain matrix operating on engine measurements are used to update the filter estimates and residuals. Sensor failures were detected and isolated by a threshold comparison of the individual residual components. Thresholds are determined by sensor noise statistics. Only hard failures are considered. To accommodate failures, faulty measured values are replaced by sensor estimates from the filter. The approach was successfully demonstrated on a detailed, real-time, nonlinear hybrid computer simulation of the engine. The detection, accommodation, and control logic are implemented in a microprocessor-based control; also in real time. Successful operation for single hard sensor failures is demonstrated at sea-level-static conditions for power chops and bursts in the idle to full take-off power range. This work, referred to as Failure Indication and Corrective Action (FICA), serves as the theoretical foundation for a significant portion of the work in the application of AR to turbine engines. Further applications based on FICA are given in a subsequent section. 
Next, DeHoff and $\mathrm{Hall}^{12}$ report a largely theoretical study that developed a unified framework to achieve engine performance monitoring, trending, and sensor fault DIA. This framework is based upon maximum-likelihood state and parameter estimation methods. A simple turbojet example is used to illustrate the application of a maximum-likelihood-based, on-line, sequential-processing, parameter estimation algorithm to the detection of sensor failures.

Sahgal and Millerl3 report on the design of a full-order observer that reconstructs fan turbine inlet temperature for an F100 engine. The observer is based upon a fifth-order scheduled state-space model with four inputs: fuel flow, nozzle area, and compressor and fan variable geometries; and four outputs: fan and compressor speed, and compressor discharge temperature and pressure. Observer performance is compared with a full nonlinear digital simulation of the engine at sea-level-static conditions. The reconstructed temperature tracks the actual temperature quite well. The analytical study proposes to use the reconstructed temperature to accommodate for fan turbine inlet sensor failures.

The next three papers $14-16$ by Leininger and Behbehani report the application of the generalized likelihood ratio (GLR) technique to the QCSEE. The GLR technique is a hypothesis-based test with the time and type of failure unknown. Under linear, Gaussian assumptions, if the Kalman-Bucy filter residuals are found to be nonwhite, a failure is declared. Next, various likelihood ratios are compared to determine the most probable failure time and type. The GLR method is used to detect and isolate hard and soft failures. Both single and multiple actuator and sensor failures were considered. 
Detection and isolation studies are conducted by simplified simulation of the QCSEE. This simulation included six outputs: fan and compressor speeds, engine inlet static pressure, fan inlet duct static pressure, combustor pressure and compressor discharge pressure; and three inputs: fuel-metering valve position, fan nozzle actuator position, and fan pitch angle. A linearized, eight-state model was used in the Kalman-Bucy filter. Successful detection and isolation of multiple sensor and actuator failures with noisy sensors and imperfect modeling were demonstrated. Accommodation by control reconfiguration using nonsquare multivariable Nyquist array methods was proposed. Designs were obtained but not demonstrated by simulation.

A doctoral dissertation by Meserole 17 uses detection filter theory to design a filter that detects sensor failures in an F100 engine. Similar to the Kalman filter, the detection filter incorporates a dynamic process model and generates error residuals. However, unlike the Kalman filter, a detection filter is designed to respond to a component failure with a residual that has a fixed, usually unique, direction. Also, this direction is independent of failure mode. Thus, sensor failures can be detected and isolated by detecting the occurrence of these fixed-direction residuals. A sixth-order state-space linear model with scheduled coefficients is used in the detection filter. Filter operation and detection capability are demonstrated using a detailed nonlinear digital simulation of the F100 engine. Fifteen components are checked for failure: the inlet pressure and temperature sensors, the fan and compressor speed sensors, the burner and augmentor total pressure sensors, the fan outer-diameter discharge and turbine inlet total temperature sensors, the fuel system, the nozzle, bleed, fan guide vane, and compressor stator vane actuators, and the high- and 
low-pressure turbines. Five inputs are considered: fuel flow, nozzle area, fan guide vane and compressor stator vane positions, and bleed. Filter performance was studied for sensor failures and component changes (failures) at sea-level-static conditions for bias and scale-factor changes. Failures were detected for 2 to 5 percent changes in one or more output measurements. Minimum failure size for successful isolation is summarized by component in Table II.

A paper by Leininger 18 examines the impact of an inaccurate model on innovations-based detection and isolation procedures. The paper demonstrates that model inaccuracies appear as biases in the innovations (residuals). These biases are identified by a Student's " $t$ " test. The " $t$ " test is then related to a recursive GLR detector using a sequentially updated Kalman filter. Model bias error is removed from the innovations data to remove the effect of model degradation and to allow more accurate soft and hard failure detection. Also, a finite-width-window sequential "t" test is used to update the bias term and provide a means of sensor failure detection and isolation. The theory was applied to an eighth-order linear model of the QCSEE. Model eigenvalues were perturbed by 10 percent to simulate model error. The " $t$ " test successfully removed the bias, tracked a sensor drift followed by a low-frequency sinusoidal sensor bias, and exhibited a fail-heal-fail detection pattern for the sinusoidal test.

The next three papers present basic research in robust detection, isolation, and accommodation of sensor failures. This research focuses on one fundamental question: How accurately must engine dynamics be modeled for successful DIA? A definitive answer to this question would establish the quantitative tradeoffs between complexity, detection time, and detection performance. An alternative viewpoint would be to define the robustness of 
a DIA algorithm to model inaccuracies or uncertainty. Two different approaches have been identified to the solution of this problem.

The research of Refs. 19 and 20 is based upon the concept of redundancy, or parity, relations. These relationships among the measured system variables incorporate all possible redundant information available. Modeling uncertainty affects the reliability of these parity relations. For a quantified level of uncertainty, all parity relations can be ranked from most to least reliable. This allows the more reliable parity relations to be used to generate DIA strategies that are as robust to uncertainty as possible. A three-step design process is presented. First, the parity relations are rank-ordered using a robustness metric. That set of relationships with acceptable robustness is identified. Second, the coverage (probability of detection for all failures) for this set of relationships is assessed. Finally, the ability of the set of parity relations to distinguish each failure mode from the others is assessed, again using a metric-based analysis. Iterations through this process are possible in order to expand the original set of relationships and to improve coverage or distinguishability by incorporating decreasingly robust parity relations. The parity relations can be generated efficiently from either a time- or frequency-domain description of the average process. The average process is defined as

$$
\bar{A}=\sum_{\ell=1}^{n} \rho_{\ell} A_{\ell}
$$

where $A_{\ell}$ represents the $\ell$ th set of model parameters and $\rho_{\ell}$ the a priori probability that $A_{\ell}$ is correct. The methodology has been applied to the preliminary design of a robust DIA system for an F100 engine. 
The research of Ref. 21 is based upon the extension of recent advances in robust control system design to sensor DIA and estimator design. Model uncertainty effects on DIA robustness are quantified using conic sector uncertainty properties. Here, uncertainty that is bounded in a conic sector in the frequency domain, and which then propagates through a system, remains bounded by a conic sector. These sectors determine quantitatively the performance/robustness trade-off. This frequency-domain description of uncertainty along with frequency-shaped filter yields optimally robust innovations to model uncertainty. Thus, sensor failure detection based upon these innovations will also be robust.

The design process makes use of a threshold selector. The threshold selector determines the minimum detectable failure size for a given noise level, failure type, false-alarm rate, and model uncertainty description. This threshold selector determines maximum achievable performance for the given set of constraints. Optimally robust (to modeling errors) residuals are generated using filters designed using the internal model principle and frequency shaping. The results of this methodology are applied to the preliminary design of sensor DIA logic for an F100 engine.

Reference 22 presents an investigation of a variation of hardware redundancy to improve soft failure DIA capability. This feasibility study examines a multiengine approach (in this case two engines) to soft failure DIA. The underlying principle is to use a like sensor measurement from one engine as redundant information to improve DIA capability on another engine. This approach incorporates a model of potential engine differences, an average engine model, and decision logic. By looking at the sum and differences of redundant sensed values for the two engines, measured average and differential performance is obtainable. These are compared to the 
average and difference engine models contained in the DIA logic. This additional information allows improved DIA performance over a single-engine concept. This concept is demonstrated using a digital nonlinear simulation of two Fllo engines.

The final paper in this section 23 determines the theoretical limits of failure detectability of sensor failures in systems with modeling errors. A method, called the reachable measurement intervals (RMI) method, is derived which is based upon this determination and which performs at the limit of detectability. This method is based upon a linear, state-space model of the system and bounds on the uncertainties of the model parameters. The RMI, which are the smallest possible thresholds, are computed using an optimization procedure based upon the maximum principle. Measurements which lie outside this interval indicate a failure. The method was applied to a hypothetical turbofan engine simplified simulation (HYTESS) 24 . High performance failure detection was demonstrated for a fan speed measurement at a single operating point, for small fuel perturbations.

\section{AR Technology Development}

Based upon the encouraging, but preliminary, results of the AR technology base, several technology development programs were begun. The overall objective of these programs is the full-scale engine demonstration of improved control system reliability using AR technology. These important AR development programs are: (1) Advanced Detection, Isolation, and Accommodation (ADIA), (2) Energy-Efficient Engine ( ${ }^{3}$ ) FICA, (3) Full Authority Digital Electronic Control (FADEC) FICA,(4) Digital Electronic Engine Control (DEEC) sensor DIA, and (5) Analytical Redundancy Technology for Engine Reliability Improvement (ARTERI). Also included is a discussion of the sensor redundancy approach used on the PW2037 engine. 


\section{A. ADIA}

The objective of the ADIA program is to demonstrate a viable DIA concept based upon advanced methodologies. The ADIA program consists of four parts: development, implementation, real-time evaluation, and demonstration.

The development of the ADIA algorithm is reported by Beattie et al 25,26 Here advanced detection and filtering methodologies were compared to develop a viable ADIA concept. Comparisons were made on an F100 engine and F100 multivariable control (MVC) 27 testbed system. The type and severity of sensor failures were carefully defined. Typical state-of-the-art transducers were selected. Failure characteristics were defined and quantified according to the predominant failure categories of out-of-range, drift, and noise. Next, a failure mode and effects analysis was conducted to classify the various failure modes as critical or noncritical. Critical failures were defined as those that resulted in surge, a 10 percent or larger thrust variation, or a rotor overspeed. This classification was accomplished over the full operating range of the F100 engine. Five competing DIA concepts were developed by combining available detection and filtering technologies. These five concepts were specifically formulated to span as many applicable technologies as possible.

Since competing technologies were to be compared, a scoring system was developed. The scoring system evaluated the concepts for (1) exceeding minimum transient and steady-state operation requirements, (2) detection and isolation effectiveness, and (3) the qualitative benefits of bettering the requirements of item 1 . Using the scoring system and a simplified simulation of the testbed system, the five concepts were screened. Two concepts were selected for a more detailed comparison. Based upon this 
second screening, one concept was selected for evaluation on a detailed nonlinear simulation of the testbed system. This detailed evaluation included simulated sensor failures for both steady-state and transient operation throughout the entire engine operating range. This evaluation showed the ADIA approach to be (1) viable for gas turbine applications, and (2) more systematic and straightforward when compared to a parameter synthesis approach.

An accurate model of the engine is required to achieve high performance failure detection. The ADIA algorithm uses a simplified simulation of the engine. Scheduled functions of engine performance define the steady-state portion of the simplified simulation. A scheduled state-space system forms the basis of the dynamic portion of the simplified simulation. In total, linear state-space models at 119 different operating points were used that uniformly span the entire flight envelope. Each individual element of the state-space matrices was corrected to reduce data scatter and then scheduled by a nonlinear polynomial of selected model output variables over the flight envelope. This approach yields a model with linear structure that maintains the essential nonlinearities of the engine. A complete description of this modeling technology, as applied to the development of a hypothetical turbofan engine simplified simulation (HYTESS), is given by Merrill et al.24 A comparison of the response of the simplified simulation with actual engine performance demonstrates the excellent estimation capability of the simplified simulation. The ADIA algorithm incorporates this simulation and Kalman filter logic to improve these estimates further (Fig. 2).

The test-bed system with ADIA and MVC logic is shown in Fig. 3 . The ADIA algorithm consists of three elements: (1) hard failure detection and isolation logic, (2) soft failure detection and isolation logic, and (3) an 
accommodation filter. The algorithm detects two classes of sensor failures, hard and soft. Hard failures are out-of-range or large bias errors that occur instantaneously in the sensed values. Soft failures are small bias errors or drift errors that accumulate relatively slowly with time.

The algorithm consists of an extended steady-state Kalman filter, called the accommodation filter, that generates sensor estimates and residuals based upon the previously described simplified engine simulation. These residuals are compared to thresholds for hard failure detection and isolation. Soft failure detection and isolation is accomplished using a bank of six Kalman filters (one for each sensor failure and one for the no failure case) and a likelihood ratio test of the five different filter residuals (Fig. 4). The likelihood ratio test calculates a weighted sum of squared residuals (WSSR) statistic for each of the six filters. This statistic represents the $\log$ of the likelihood of the particular residuals being true. Substracting the likelihoods of the five failure hypothesis filters from the normal mode likelihood yields likelihood ratios. The test then compares the maximum likelihood ratio, which represents the maximum likelihood of a particular sensor failure hypothesis being true to a threshold. The threshold is adaptive and expands during transients to account for high frequency modeling error. The adaptive threshold enables an 80 percent improvement in steady-state failure detection performance. After a failure is detected and isolated, the faulty information is removed from the accommodation filter by reconfiguration. Estimates of all sensor outputs are still produced, however, now they depend upon the set of unfailed measurements. The ADIA algorithm interfaces with the MVC algorithm in two ways. First, it supplies the linear quadratic regulator (LQR) with estimates of the engine outputs at all times. Second, it supplies the 
integral control logic with actual sensed values in the normal mode. An individual sensed value is only replaced with an estimate when a failure occurs and is detected and isolated.

The second part of the ADIA program is the real-time microprocessor-based implementation of the MVC and ADIA algorithms. DeLaat and Merril128 describe a preliminary implementation of two 5-MHz, Intel8086-based microprocessors operating in a paralle1-processing environment. The first computer contains a fixed-point, assembly language, real-time implementation of the MVC that had been implemented and evaluated previously.29 The second computer contains the detection and accommodation logic implemented in floating-point FORTRAN. Subsequent work has incorporated a third microprocessor into the implementation and replaced the 8086-based microprocessors with 8-MHz 80186-based microprocessors. 30 In this third computer the five isolation filters are implemented, again using floating-point FORTRAN.

The total control cycle time is $40 \mathrm{msec}$. Data are transferred between CPU's through dual-ported memory. Synchronization between CPU's is achieved through interrupts. The total memory requirement for the three CPU's is $54 \mathrm{~K}$ bytes for the algorithm and $17 K$ bytes for the real-time executive. In all 'cases the code and constants were about 65 percent and the data or variables about 35 percent of the total memory required.

In the evaluation phase, 31,32 an evaluation of algorithm performance was obtained using a real-time engine simulation running on a hybrid computer and microprocessor implementation described above. The objectives of the evaluation were: (1) validate the algorithm for sensor failure detection, isolation, and accommodation (DIA) effectiveness; (2) document algorithm performance; (3) validate the algorithm's real-time 
implementation; and (4) establish a data base for the demonstration phase of the ADIA program. All these objectives were successfully accomplished.

In the demonstration phase 33 the ADIA algorithm was tested on a full scale F100 engine in the Lewis Research Center altitude test facility. The engine test successfully demonstrated the predicted performance of the ADIA algorithm on realistic hardware over a wide range of engine operating conditions. These conditions include altitude, Mach number, and power variations.

The criteria used to evaluate detection, isolation, and accommodation performance were: (1) minimum detectable bias values and drift rates, (2) elapsed time between sensor failure and detection, (3) steady-state performance degradation after failure accommodation, and (4) transient response of the engine to the filter and control reconfiguration resulting from failure accommodation. Although the engine test demonstrated the capability to detect, isolate, and accommodate both hard and soft sensor failures, only soft failure detection results are presented. This is because soft failure detection is more difficult than hard failure detection, and is therefore a more interesting problem. Two soft failure modes were studied, bias and drift.

The minimum detectable magnitudes of soft sensor bias failures for engine exhaust nozzle pressure (a variable closely related to engine thrust) demonstrated during testing are summarized in Fig. 5. Also shown in this figure for comparison are those minimum detectable magnitudes predicted by the real-time hybrid evaluation of the ADIA algorithm. 32 In general there is good agreement between predicted and observed detection magnitudes. This agreement demonstrates the excellent fidelity of the model used in the algorithm and the simulation used in the evaluation. Many of the values are 
the same. This is a result of the testing procedure. To minimize engine test time, the known evaluation predicted values were tested first. If the algorithm successfully detected the failure at the predicted magnitude, then that was the assumed minimum detectable value for the demonstration. If the detection was missed, the failure magnitude was increased until successful detection was demonstrated on the engine. Thus the demonstration values recorded in Fig. 5 are always equal or greater than the predicted ones (except for $\mathrm{N} 2$ and PT4 at $55 \mathrm{~K} / 2.2$ ). Although this was a conservative approach, it was clear from the test results that only minimal improvements over the predicted performance were possible at a limited number of operating points.

The times to detection for the soft bias failures were all less than $0.1 \mathrm{sec}$. The steady-state accommodation performance for this class of failure is shown in Fig. 6. Percent changes in engine pressure ratio (EPR)

$$
\Delta E P R=100^{*} \frac{(E P R T O-E P R T F)}{E P R R_{T O}}
$$

$E P R=$ Exhaust nozzle pressure/engine inlet pressure where EPR TO is the steady-state EPR before the failure and EPR TF is the steady-state EPR after the failure as shown for several operating points demonstrating subsonic and supersonic operation at military and medium power levels. Medium power is approximately half of military power. The parameter EPR is almost linearly related to engine thrust and is therefore a good measure of engine performance. All values are well below the 10 percent critical level except for operating condition $50 \mathrm{~K} / 1.8$ results which show a 12 percent change in thrust for a PT6 sensor failure. This result is due to the low nominal value of PT6 at this condition (16.5 psi). The actual change in PT6 caused by the modeling error in the accommodation 
filter is only 2 psi and is considered relatively small. It appears large when compared with the low nominal value.

The minimum detectable drift magnitudes were determined by finding the smallest detectable drift failure such that a failure was detected approximately $5 \mathrm{sec}$ after failure inception. Initial trial magnitudes were determined as before from predicted simulation values. The results are given in Fig. 7. Again shown in this figure for comparison are those minimum detectable magnitudes predicted by the real-time hybrid evaluation of the ADIA algorithm. As expected from the bias failure results, there is, in general, good agreement between predicted and observed detection magnitudes. Steady-state accommodation performance for subsonic and supersonic conditions at full and medium power for sensor drift failures was very good with most thrust changes being small and with none larger than the 10 percent level.

Additionally, detection performance for sequential failures was demonstrated. At condition 10 K/0.6 six different sequences of soft failures were injected into the test bed system at medium power and one sequence was demonstrated at intermediate power. One example of a failure sequence was to fail N1, then 4 sec later fail N2, then PT4, and then PT6. In each case the algorithm successfully detected and accommodated each sensor failure in the correct order. Steady-state thrust changes are all close to the critical 10 percent level except for the intermediate power case. In each case these changes were experienced well into the transient when only two of the five sensors remained unfailed. These tests demonstrate the ability of the algorithm to continue to successfully perform even after most of the sensors have failed. 
Finally, a simultaneous soft failure of PT4 and PT6 (both failed at the same instant of time) was injected into the engine system. The algorithm, although not designed for this extremely low probability event, successfully detected and accommodated this failure scenario. The change in EPR is about 1.5 psi or less than 7 percent.

All of the above failures were electronically generated using special purpose hardware to give timed and repeatable results. The generated failures represent realistic sensor failures which were injected into the engine control system. However, during engine testing an unplanned failure of actual sensor hardware was detected by the ADIA logic. Additionally, there were no missed detections of sensor hardware failures by the ADIA logic. The sensor hardware failure was associated with the FTIT measurement. About $13 \mathrm{sec}$ after the start of a nozzle pressure sensor failure detection experiment, an FTIT soft failure was detected. From the sensed FTIT signal shown in Fig. $8(a)$ it is clear that some transient anomaly occurred. The likelihood ratio for FTIT given in Fig. $8(b)$ shows the detection taking place (note that the detection threshold for this case is twice the normal size) at $13 \mathrm{sec}$. The failure mode is indicative of a momentary "singing" of a signal conditioning amplifier. Although conclusive proof of a hardware failure was not obtained because of its nonrepeatability, this failure mode was not observed again once the suspected signal conditioning amplifier was replaced.

Two experiments were used to demonstrate the successful accommodation, or post-failure performance, of sensor failures. The first experiment consisted of injecting, detecting, and accommodating a single sensor failure and then commanding an acceleration-deceleration pulse transient. Engine performance, measured on the average absolute value of control error over 
the transient, with this accommodated failed sensor is compared to normal mode engine performance. Eighteen of these single failure pulse tests were performed at five different operating points.

In general the change is performance is small for each experiment. The largest fan speed error change of about $160 \mathrm{rpm}$ is, in fact, quite small when compared to the typical operating range of fan speed (5000 to 10000 rpm). Results for an engine acceleration-deceleration pulse response with a single exhaust nozzle pressure sensor failure and its baseline response are shown in Fig. 9. Results are shown for both fan speed and exhaust nozzle pressure. In general performance was good since the desired or request values were closely maintained. A slight drop in actual nozzle pressure can be seen but this is acceptable. In all other cases the accommodated single failure transient performance was good. The fluctuations evident in nozzle pressure at the high power level are caused by an airflow interaction between the altitude test cell and the engine.

The second accommodation performance experiment demonstrated the excellent accuracy of the engine model. In this experiment all the engine output sensors were failed and accommodated. Then, the engine was commanded to respond to a PLA pulse transient. Two all-sensors-failed pulse transient experiments were performed at different conditions. At the first condition (altitude $10000 \mathrm{ft}$, Mach number $=0.6$ ) the transient was from idle to about 75 percent of full power. As confidence in the ability to safely control the engine without engine output sensors increased, a second test went to full power. For the first condition fan speed and exhaust nozzle pressure results are shown in Fig. 10. Here excellent performance was demonstrated. Little or no overshoot was observed and engine steady-state performance was good. This demonstrates the capability of safe, predictable engine 
operation without any engine feedback information over a slightly restricted power range. Again the fluctuations in nozzle pressure at high power were caused by an airflow interaction between the facility and the engine. Performance for the second condition was similar.

Based on the results of the engine test several conclusions have been reached. First, the ADIA failure detection algorithm works and works quite well. Sensor failure detection and accommodation were demonstrated at eleven different operating points which included subsonic and supersonic conditions and medium and high power operation. The minimum detectable failure magnitudes represent excellent algorithm performance and compare favorably to values predicted by simulation. Accommodation performance was excellent. Transient engine operation over the full power range with single sensors failed and accommodated was successfully demonstrated. Open loop engine operation (all sensors failed and accommodated) over at least 75 percent of the power range was also demonstrated at two different operating conditions.

Second, the algorithm is implementable in a realistic environment and in an update interval consistent with stable engine operation. Off-the-shelf microprocessor based hardware and straightforward programming procedures, including FORTRAN and floating point arithmetic, were used. Parallel processing was also used and shown to be an effective approach to achieving a real-time implementation using off-the-shelf (cost effective) computer resources.

\section{B. $E^{3}$ FICA}

The $E^{3}$ program is developing technology to improve the energy efficiency of future commercial transport aircraft engines. A FADEC based upon the bit-slice AMD 2901 microprocessor is used to implement the control 
and FICA logic for the engine developed under this program. The FICA logic is based upon the concept of Spang and Corley. 11 Here, a sixth-order extended Kalman filter is used to generate seven sensor estimates: fan and core speed, compressor inlet and discharge temperatures, turbine discharge temperature, fuel-metering valve position, and compressor discharge static pressure. The Kalman filter uses a dynamic model of simplified engine aerothermodynamics and rotor dynamics. Actuator and sensor dynamic models are also included. This model accurately describes the engine over the full-power range and flight envelope using simplified component modeling. The Kalman gain matrix is computed at a key operating point using a linearized engine model. Sensor failures are detected when the sensed versus estimated difference is greater than a prespecified tolerance. Out-of-range failures are also detected. The tolerance is estimated by statistical analysis and adjusted during simulation trials. Accommodation of failures is accomplished by replacement of sensed values with estimated values. A nonlinear real-time simulation evaluation of the FICA logic showed that the filter estimate tracked the sensed values within the specified tolerance and successfully detected, isolated, and accommodated all hard sensor failures except fuel-metering valve position. The $E^{3}$ FICA logic does not detect slow drift, i.e., soft, sensor failures.

\section{FADEC FICA}

Under the FADEC program 35 AR techniques (in particular, FICA) were applied to two engines, a Joint Technology Demonstrator Engine (JTDE) and the F404 afterburning turbofan engine. Each of these applications is discussed below.

The JTDE FICA was designed for a variable-cycle engine with seven manipulated variables and nine sensed variables. The engine model used in 
the JTDE FICA is a second-order, dynamic pseudolinear model valid throughout the flight envelope. The model is updated by an observer. Observer gains were chosen as the reciprocals of corresponding engine model steady-state gains at a high-power condition. Gains were then adjusted to achieve adequate stability margins. For failure detection, sensor model errors were compared to a preset threshold. Substitution of estimated variables was demonstrated using a simulation and, subsequently, a full-scale engine. The engine demonstration was limited to sea-level-static conditions and single substitutions. Single substitutions for fan speed, compressor discharge static pressure, and compressor inlet temperature were performed successfully. Also demonstrated by simulation in this program was the application of FICA techniques to actuator sensor failures. In particular, fuel flow and nozzle area actuator hard out-of-range sensor failures were detected and accommodated.

A second application of the FICA technology was to the F404 engine. The F404 is an afterburning turbofan engine with a rear variable-area bypass injector to permit selective cycle rematch. The rear injector adjusts the bypass-to-core-air ratio to match cycle demands. The engine includes five inputs and five outputs. A simplified, fourth-order, component-level mode ${ }^{36}$ is used in the FICA system. The model is accurate throughout the flight envelope and was implemented in FADEC microprocessor hardware in a 0.01-s update time increment. The model along with the FICA update logic was checked against actual engine operation during full-scale engine tests at sea-level-static and altitude conditions. ${ }^{37}$ Steady-state and transient model accuracies were judged to be excellent. Single, double, and triple substitutions of FICA-generated estimates were performed successfully during the engine tests. These combinations are summarized in Fig. 11. Actuator 
FICA was also demonstrated successfully for exhaust nozzle hard open and closed failures. Thrust level in these cases was maintained by adjusting the gas generator speed reference schedule.

D. DEEC DIA

The DEEC system 38 is a digital full-authority engine control containing selectively redundant components and fault-detection logic. The system also contains a hydromechanical backup control. Most of the sensors in the control are hardware-redundant. However, failures of the inlet static pressure (PS2), burner pressure (PB), and fan turbine inlet pressure (FTIT) are covered using a form of AR called parameter synthesis.

In parameter synthesis an estimate of one measured variable is synthesized from an algebraic function of one or more different measured variables. This relationship is static, i.e., no explicit dynamics are included. If PS2 fails a range check, a synthesized PS2 is determined from $P B$, compressor speed, $N 2$, and inlet total temperature, TT2. IF PB fails, a synthesized PB is calculated from inlet total pressure, PT2, N2, and TT2. Fault detection of $P B$ failures is based upon a comparison of measured and synthesized values. A comparison tolerance of \pm 25 percent determines failures. This large tolerance precludes detection of soft failures. Both PS2 and PB failures are accommodated by substitution.

There are two groups of FTIT sensors. This allows hardware redundancy. However, if both FTIT sensor groups fail a range check, synthesized FTIT is substituted into the control. Synthesized FTIT is a function of $P B$ and $P T 2$.

The DEEC DIA logic was verified by closed-loop bench testing. Simulated sea-level and altitude engine transients were performed. Faults were intentionally produced to evaluate DIA effectiveness. Subsequent 
sea-level and altitude full-scale engine tests uncovered no new problems with the DIA logic. A series of flight tests of an Fl5 aircraft with an F100 engine and DEEC control further demonstrated the DEEC Logic 39 . During the flight program, the DEEC DIA logic did not detect any false alarms and did not cause any reversions to backup hydromechanical control. Two sensor failures occurred during the flight program. One, inlet temperature, was covered by redundant hardware. The second, exhaust nozzle pressure, failed to a high scale sensor limit. Appropriate accommodation action was taken by the logic in each case.

Neither of the two sensor failures encountered in the flight-test program demonstrated the AR-based logic of the DEEC DIA. In a subsequent flight test program 40 the objective was to induce selected hard sensor faults and evaluate the resulting actions of the control. The test program included both an extensive ground-thrust stand evaluation and a flight test. In flight failures were introduced at steady-state conditions and during throttle transients. Throttle transients were performed by inducing the failures before and during the throttle movement. The sensors failed during the flight test included the compressor inlet variable geometry sensor, PS2, PB, and FTIT. Most failures were detected and accommodated. However, a recreation of a broken line (hard) PB failure went undetected. $\mathrm{Pilot}$ response to aircraft performance after accommodation was favorable.

\section{E. ARTERI}

ARTERI 41 is a program to develop AR techniques based upon FICA to the point where they may be employed in a full-scale engine development program. Both hard and soft failures must be covered over the full range of engine power and flight conditions. A component tracking module, which tunes the engine model to match the actual engine by updating engine model 
dynamic states, inputs, outputs, and component performance parameters, is used to extend FICA to include a soft failure DIA capability. Nonlinear simulation results have demonstrated the ability of the logic to discriminate among sensor, and actuator hard and soft failures.

The real-time implementation and demonstration of the ARTERI logic on an actual engine remain to be accomplished. Also, the component tracking filter adapts the engine model at a selected operating point. Its global capabilities need to be improved to allow soft failure detection during large excursions in power or operating condition.

F. PW2037

The PW2037 engine is a modern, high-bypass-ratio turbofan engine and is the first to incorporate a completely digital, full-authority electronic control system. ${ }^{2}$ The control is engine-mounted and dual-channeled to meet reliability requirements. As part of the control's redundancy management strategy, a combination of hardware and software sensor redundancy is used to ensure engine operability whenever the capability is available. Dual hardware is used for seven sensors (two speeds, two pressures, two temperatures, and thrust lever angle). All of these sensors are covered by channel-to-channel comparisons, as well as software range and rate checks, to detect failures. In the case of the two engine speeds and the two pressures, sensor failures are further covered by comparisons to synthesized estimates. In the case of a dual-channel failure (both low-spool-speed sensors, for example), operation continues using the synthesized estimate of low spool speed. The two pressures and high spool speed are synthesized from low spool speed using a parameter synthesis method. Low spool speed is synthesized from high spool speed. 


\section{AR Technology Assessment}

From the preceding survey an assessment of the relative state-of-the-art of applied AR can be obtained. The results presented in the technology base, and summarized in Table I, demonstrate the feasibility of AR-based DIA. In particular, straightforward range or rate checks have provided successful detection of hard sensor failures. Further, advanced DIA approaches based upon advanced statistical decision theory and optimal filtering have demonstrated soft failure DIA feasibility. However, this soft failure DIA capability is obtained at the cost of increased computational complexity. This additional complexity consists of two parts: the filtering and decision-making logic, and a more accurate, and therefore more detailed, model. These results also demonstrate a tradeoff between ability to accurately detect and time to detect. Where hard failures can be detected almost instantly, soft failures are reliably detected only after some finite amount of time. This time to detect is a function of threshold level, which determines detection reliability, required model accuracy, and logic complexity. Usually for soft failures, more time is available before accumulated error is damaging.

Further results presented in the technology development section demonstrate AR-based DIA capability for hard and soft sensor failures on full-scale engines over a wide range of power and flight conditions. State-of-the-art operational systems, such as the DEEC and the PW2037 control, use only limited AR in combination with more extensive hardware redundancy.

The work presented in this survey clearly emphasizes the fundamental importance of modeling in successful DIA. A model detailed enough for accurate DIA throughout the flight envelope is a significant technical 
challenge. Expectantly, when faced with a difficult technical problem, different approaches are pursued. Three different modeling approaches have been used: (1) parameter synthesis, (2) pseudolinear, and (3) simplified component. Both the parameter synthesis and simplified component modeling approaches have been used in successful hard failure DIA on full-scale engines. The pseudolinear method has been demonstrated for both hard and soft failure DIA on a full-scale engine. Each approach has its own advantages and disadvantages.

The parameter synthesis approach, which was used in the DEEC DIA and the PW2037, is simple to understand and straightforward to implement. Explicit dynamics normally are not included. However, this simplicity implies a less accurate model. Also, the most accurate interrelationships between measured and synthesized variables can not be identified easily or systematically. Model modifications are made easily.

The simplified component approach, which was used in the FADEC FICA, results in more accurate models than the parameter synthesis approach. Simplified component models are based upon detailed nonlinear engine simulations. Detail is selectively removed from the detailed simulation to maximize simplicity while maintaining accuracy. This process requires a great deal of judgment and is not straightforward or systematic. In addition, simplified model performance is not easily predicted. A simplified component model relates naturally to the physics of the actual engine and, therefore, is readily understandable. However, modification of a simplified component model is not straightforward since changes in component performance can unpredictable effect on model performance.

The pseudolinear modeling method used in the ADIA algorithm, is a very organized, systematic approach. However, to achieve accuracy through a wide 
range of conditions requires a large amount of stored data. The relationship of a pseudolinear model with engine physics is not as straightforward as for a simplified component model. However, steady-state and dynamic model performance can be separated and modified independently. Due to the linear structure of the model equations, analys is and performance prediction is much easier with a pseudolinear model than with parameter synthesis or simplified component models. In addition, the complexity/accuracy tradeoff is defined more clearly for a pseudolinear model.

IV. Concluding Remarks

This chapter has surveyed the technology base and technology applications for analytical redundancy (AR)-based sensor fallure detection, isolation, and accommodation (DIA) strategies for gas turbine engines. Several observations and conclusions are made. Comparisons of PW2037 technology with that of the F8 digital fly-by-wire program, or the approach used in the ADIA program with that proposed by Montgomery and Caglayan, 42 show that engine AR technology of ten builds or expands upon technology developed for flight controls. Also, modeling is the key issue in the success of AR techniques. Three types of models are used. Each has its advantages and disadvantages and no clear preferred type emerges. Because of this strong dependence of performance on modeling accuracy, fundamental questions about detection performance and robustness have been posed and addressed in robust DIA programs. Finally, simulation or full-scale engine testing has conclusively shown the feasibility of AR-based DIA for hard and soft failures. 


\section{REFERENCES}

1. Baker, L.E., Warner, D.E., and Disparte, C.P. (1981). "Design of Fault Tolerant Electronic Engine Controls," AIAA Paper 81-1496.

2. Kuhlberg, J.F., Newirth, D.M., Kniat J., and Zimmerman, W.H. (1984). "Integration of the PW2037 Engine Electronic Control System in the Boing 757 Airplane," SAE Paper 841554.

3. Deckert, J.C., Desai, M.N., Deyst, J.J., and Willsky, A.S. (1977). "F-8 DFBW Sensor Failure Identification Using Analytical Redundancy," IEEE Trans. Automatic Control, AC-22, 795-803.

4. Wallhagen, R.E., and Arpasi, D.J. (1974). "Self-Teaching Digital-Computer Program for Fail-Operational Control of a Turbojet Engine in a Sea-Level Test Stand," NASA TM $X-3043$.

5. Hrach, F.J., Arpasi, D.J., and Bruton, W.M. (1975). "Design and Evaluation of a Sensor Fail-Operational Control System for a Digitally Controlled Turbofan Engine," NASA TM X-3260.

6. Ellis, S.H. (1976). in "3rd International Symposium on Air Breathing Engines," (D.K. Hennecke and G. Winterfeld, eds.), pp. 171-186. Deutsche Gesellschaft fuer Luft und Raumfahrt, Cologne.

7. de Silva, C.W. (1976). "Sensor Failure Detection and Output Estimation for Engine Control Systems," M.S. Thesis, University of Cincinnati.

8. de Silva, C.W. (1982). Arabian J. Sci. Eng., I, 45-53.

9. Wells, W.R., and desilva, C.W. (1977). in "Proceedings of Joint Automatic Control Conference," Vol. 2, pp. 1493-1497. IEEE, Piscataway, NJ.

10. Wells, W.R. (1978). "Detection of Sensor Failure and Output Reconstruction for Aircraft Engine Controls," AIAA Paper 78-4. 
11. Spang, III, H.A. and Corley, R.C. (1977). "Failure Detection and Correction for Turbofan Engines," General Electric Co., Schenectady, NY, Rpt. No. 77CRD159.

12. DeHoff, R.L. and Hall, W.E. Jr. (1978). "Advanced Fault Detection and Isolation Methods for Aircraft Turbine Engines," Systems Control Inc., ONR-CR-215-245-1. (Avai1. NTIS, AD-A588991.)

13. Sahgal, R.K. and Miller, R.J. (1979). in "Proceedings of Joint Automatic Control Conference," pp. 381-386. IEEE, Piscataway, NJ.

14. Leininger, G.G. and Behbehani, K. (1980). in "Proceedings of Joint Automatic Control Conference," Vol. 2, Paper TP4-B. IEEE, Piscataway, NJ.

15. Behbehani, K. (1980). "Sensor Failure and Multivariable Control for Airbreathing Propulsion Systems," Ph.D. Thesis, University of Toledo. (Also, NASA CR-159791.)

16. Behbehani, K. and Leininger, G.G. (1980). in "Propulsion Controls 1979," NASA CP-2137, pp. 139-143. National Aeronautics and Space Administration, Washington, D.C.

17. Meserole, J.S. Jr. (1981). "Detection Filters for Fault-Tolerant Control of Turbofan Engines," Ph.D. Thesis, Massachusetts Institute of Technology.

18. Leininger, G.G. (1981). in "Proceedings of Joint Automatic Control Conference," Vol. 2, Paper FP-3A. IEEE, Piscataway, NJ.

19. Weiss, J.L., Pattipati, K.R., Willsky, A.S., Eterno, J.S., and Crawford, J.T. (1985). "Robust Detection/Isolation/Accommodation for Sensor Failures," Alphatec Inc., Burlington, MA, TR-213. (A1so, NASA CR-174797.)

20. Pattipati, K.R., Willsky, A.S., Deckert, J.C., Eterno, J.S., and Weiss, J.S. (1984). in "Proceedings of the 1984 American Control Conference," pp. 1755-1762. IEEE, Piscataway, NJ.

21. Emmani-Naeini, A., Akhter, M.M., and Rock, S.M. (1985). "Robust Detection, Isolation, and Accommodation for Sensor Failure," NASA CR-174825. 
22. Brown, H., Corley, R.C., Elgin, J.A., and Spang, H.A. (1984).

"Multi-Engine Detection, Isolation, and Accommodation of Sensor Failures," General Electric Co., Cincinnati, OH, R84AEB359. (Also NASA CR-174846.)

23. Horak, D.T. (1988). "Failure Detection in Dynamic Systems with Modeling Errors," J. Guidance, Control, and Dynamics, Vol. 11, No. 6, 1988.

24. Merrill, W.C., Beattie, E.C., LaPrad, R.F., Rock, S.M., and Akhter, M.M. (1984). "HYTESS: A Hypothetical Turbofan Engine Simplified Simulation," NASA TM-83561.

25. Beattie, E.C., PaPrad, R.F., McGlone, M.E., Rock, S.M., and Akhter, M.M. (1983). "Sensor Failure Detection System," Pratt \& Whitney Aircraft Group, East Hartford, CT, PWA 5736-17. (Also, NASA CR-165515.)

26. Beattie, E.C., LaPrad, R.F., Akhter, M.M., and Rock, S.M. (1983). "Sensor Failure Detection for Jet Engines," Pratt \& Whitney Aircraft Group, East Hartford, CT, PWA-5891-18. (Also, NASA CR-168190.)

27. Lehtinen, B., Costakis, W.G., Soeder, J.F., and Seldner, K. (1983). "F100 Multivariable Control Synthesis Program - Results of Engine Altitude Tests," NASA TM S-83367.

28. DeLaat, J.C., and Merrill, W.C. (1983). "A Real-Time Implementation of an Advanced Sensor Failure Detection, Isolation, and Accommodation Algorithm," NASA TM-83553.

29. DeLaat, J.C., and Soeder, J.F. (1985). "Evaluation of a Microprocessor Implementation of the F100 Multivariable Control," NASA TM-87130.

30. DeLaat, J.C. and Merri11, W.C. (1988). "A Real-Time Microprocessor Based Implementation of the ADIA Algorithm," NASA TP___ (to be published).

31. Merri11, W.C. and DeLaat, J.C. (1986). "A Real-Time Simulation Evaluation of an Advanced Detection, Isolation and Accommodation Algorithm for Sensor Failures in Turbine Engines," NASA TM- 87289. 
32. Merri11, W.C., DeLaat, J.C., and Bruton, W.M. (1988). "Advanced Detection, Isolation, and Accommodation of Sensor Failures: Real-Time Evaluation," J. Guidance, Control, and Dynamics, Vol. 11, No. 6, 1988. _(Also, NASA TP-2740.)

33. Merri11, W.C., Delaat, J.C., Kroszkewicz, S.M., and Abdelwahab, M. (1988). "Advanced Detection, Isolation, and Accommodation of Sensor Failures Engine Demonstration Results," NASA TP-2836.

34. Beitler, R.S. and Lavash, J.P. (1982). "Energy Efficient Engine (E ${ }^{3}$ ): Controls and Accessories Detail Design," General Electric Co., Cincinnati, OH, R82AEB400. (Also, NASA CR-168017.)

35. Kreitinger, T.M., et al. (1983). "Full Authority Digital Electronic Control, Phase II, Final Report - Industry Version," General Electric Company, Cincinnati, OH, R82AEB435.

36. French, M. W. (1982). "Development of a Compact Real-Time Turbofan Engine Dynamic Simulation," SAE Paper 821401.

37. Linebrink, K.L. and Vizzini, R.W. (1982). "Full Authority Digital Electronic Control (FADEC) - Augmented Fighter Engine Demonstration," SAE Paper 821371 .

38. Myers, L.P. (1984). in "Digital Electronic Engine Control (DEEC) Flight Evaluation in an F-15 Airplane," NASA CP-2298, pp. 33-54. National Aeronautics and Space Administration, Washington, D.C.

39. Myers, L.P., Macka11, K.G., Burcham, F.W. Jr., and Walter, W.A. (1982). "Flight Evaluation of a Digital Electronic Engine Control System in an F-15 Airplane," AIAA Paper 82-1080.

40. Myers, L.P., Baer-Riedhart, J.L., and Maxwell, M.D. (1985). "Fault Detection and Accommodation Testing on an F100 Engine in an F-15 Airplane," NASA TM-86735. 


\section{WTICARL PAGE IS OF POOR QUALTY}

41. Brown, H. and Swann, J.A. (1987). "Analytical Redundancy Technology for Engine Reliability Improvement, "Naval Air Propulsion Test Center, NAPC-PE-171C.

IABII 1. - SlimmaRY OF PAPIR AIIKLISUIKS

\begin{tabular}{|c|c|c|c|c|c|c|c|c|}
\hline Paper & Testlued systen & $\begin{array}{c}\text { Reference } \\
\text { model }\end{array}$ & Type of $\mathrm{OI}$ & Type of A & $\begin{array}{c}\text { Computer } \\
\text { environnent }\end{array}$ & Evaluation & $\begin{array}{c}\text { Number of } \\
\text { sensors }\end{array}$ & Miscellaneous \\
\hline $\begin{array}{l}\text { Wallhagen } \\
\text { and Arpasi } 4\end{array}$ & 385 turbojet & PS & $\begin{array}{l}\text { Hard failures via } \\
\text { rate-limit } \\
\text { threshold }\end{array}$ & Replacenient & $\left\{\begin{array}{l}\text { Real-tine } \\
\text { mini- } \\
\text { computer }\end{array}\right.$ & SLS & 2 & \\
\hline Hrach et al. ${ }^{5}$ & $\begin{array}{l}\text { If } 30 \text { real-time } \\
\text { hybrid } \\
\text { simulation }\end{array}$ & PS & $\begin{array}{l}\text { Hard failures via } \\
\text { rate-limit } \\
\text { threshold }\end{array}$ & Replacement & $\begin{array}{l}\text { Real-time } \\
\text { mini- } \\
\text { computer }\end{array}$ & $\begin{array}{l}\text { five operating } \\
\text { conditions } \\
\text { through flight } \\
\text { envelope }\end{array}$ & 4 & $\begin{array}{l}\text { Extension of } \\
\text { Ref. } 4\end{array}$ \\
\hline E11 is 6 & $\begin{array}{l}\text { Turbofan } \\
\text { nonlinear } \\
\text { digital } \\
\text { simulation }\end{array}$ & PS, PL & $\begin{array}{l}\text { Threshold check of } \\
\text { weighted-average } \\
\text { estimate }\end{array}$ & $\begin{array}{l}\text { Estimates } \\
\text { always used } \\
\text { by control } \\
\text { weighted- } \\
\text { average } \\
\text { modified }\end{array}$ & $\begin{array}{l}\text { Digital } \\
\text { simulation }\end{array}$ & SLS & 6 & \\
\hline $\begin{array}{l}\text { Wells and } \\
\text { de Silva } 7-10\end{array}$ & $\begin{array}{c}\text { Nonlinear model } \\
\text { of turbojet }\end{array}$ & $\begin{array}{l}\text { PL with } \\
\text { bank of } \\
\text { filters }\end{array}$ & $\begin{array}{l}\text { Bayesian } \\
\text { hypothesis }\end{array}$ & None & $\begin{array}{l}\text { Digital } \\
\text { simulation }\end{array}$ & sis & 2 & \\
\hline $\begin{array}{l}\text { Spang and } \\
\text { Corley } 11\end{array}$ & $\begin{array}{l}\text { QCSEE real-time } \\
\text { hybrid } \\
\text { simulation }\end{array}$ & $\begin{array}{l}\text { SC with } \\
\text { Kalman } \\
\text { filter }\end{array}$ & $\begin{array}{l}\text { Threshold } \\
\text { comparison of } \\
\text { filter residuals }\end{array}$ & Substitution & $\begin{array}{r}\text { Real-time } \\
\text { digital } \\
\text { control }\end{array}$ & SLS & 7 & \\
\hline $\begin{array}{l}\text { Detiof } f \text { and } \\
\text { Mall }\end{array}$ & $\begin{array}{c}\text { Single-spool } \\
\text { turbojet }\end{array}$ & SC & Maximum liklihood & None & $\begin{array}{l}\text { Digital } \\
\text { simulation }\end{array}$ & SLS & 1 & Theoretical study \\
\hline $\begin{array}{l}\text { Sahgal and } \\
\text { Miller }\end{array}$ & $\begin{array}{l}\text { floo nonlinear } \\
\text { simulation }\end{array}$ & $\mathrm{PL}$ & None & Substitution & $\begin{array}{l}\text { Oigital } \\
\text { simulation }\end{array}$ & Iwo conditions & 4 & \\
\hline $\begin{array}{l}\text { Leininger and } \\
\text { Behbehani } 14-16\end{array}$ & $\begin{array}{l}\text { QCSEE nonlinear } \\
\text { simulation }\end{array}$ & PL & GLR & None & $\begin{array}{l}\text { Digital } \\
\text { simulation }\end{array}$ & SLS & 6 & $\begin{array}{l}\text { Theoretical and } \\
\text { application study }\end{array}$ \\
\hline Meserole 17 & $\begin{array}{l}\text { Flo0 nontinear } \\
\text { simulation }\end{array}$ & $\mathrm{PL}$ & Detection filter & None & $\begin{array}{l}\text { Digital } \\
\text { simulation }\end{array}$ & SLS & 15 & $\begin{array}{l}\text { Theoretical and } \\
\text { application study }\end{array}$ \\
\hline Leininger ${ }^{18}$ & QCSEE simulation & Linear & "t t" test & None & $\begin{array}{l}\text { Digital } \\
\text { simulation }\end{array}$ & SLS & 3 & $\begin{array}{l}\text { Theoretical study of } \\
\text { model uncertainty }\end{array}$ \\
\hline $\begin{array}{l}\text { Weiss et al. } 19 \\
\text { and Pattipati } \\
\text { et al. } 20\end{array}$ & F100 linear & Linear & SPRT & None & $\begin{array}{l}\text { Digital } \\
\text { simulation }\end{array}$ & SLS & 5 & $\begin{array}{c}\text { Theoretical study of } \\
\text { model uncertainty }\end{array}$ \\
\hline $\begin{array}{l}\text { Emami-Naeini } \\
\text { et al. } 21\end{array}$ & Flo0 linear & Linear & Hypothesis & $\begin{array}{l}\text { Frequency- } \\
\text { weighted } \\
\text { filter } \\
\text { estimates }\end{array}$ & $\begin{array}{l}\text { Oigital } \\
\text { simulation }\end{array}$ & SLS & 5 & $\begin{array}{l}\text { Theoretical study of } \\
\text { model uncertainty }\end{array}$ \\
\hline Brown et al. ${ }^{22}$ & F110 nonlinear & Linear & $\begin{array}{c}\text { Threshold } \\
\text { checks }\end{array}$ & Substitution & $\begin{array}{l}\text { Digital } \\
\text { simulation }\end{array}$ & SLS & 9 & $\begin{array}{l}\text { Application to } \\
\text { multiple engines }\end{array}$ \\
\hline Horak 23 & HYTESS & Linear & RMI & None & $\begin{array}{l}\text { Digital } \\
\text { simulation }\end{array}$ & SLS & 1 & \\
\hline
\end{tabular}

Key: $P S=$ parameter synthesis, $S C=$ simplified component, $P L=$ pseudolinear, $S L S=$ sea level static, SPRT = sequential probability ratio test, GLR = generalized likelihood ratio, and $R M I$ = reachable measurement interval. 
TABLE II. - MINIMUM FAILURE SIZE FOR A DETECTIONa

FILTER DESIGNEO FOR AN F100 ENGINE

\begin{tabular}{|l|r|r|}
\hline \multicolumn{1}{|c|}{ Isolation } & $\begin{array}{r}\text { Minimum failure size, } \\
\text { percent }\end{array}$ \\
\cline { 2 - 3 } & \multicolumn{2}{|c|}{ Engine state } \\
\cline { 2 - 3 } & Steady & Unsteady \\
\hline Output sensors & 2 & 5 to 10 \\
Inlet sensors & 2 & 5 to 10 \\
Fuel system, exhaust nozzle & 5 to 10 & 10 to 20 \\
Compressor vanes, fan vanes & 10 to 30 & 20 to 60 \\
Rotor efficiencies & 2 & 5 to 10 \\
\hline
\end{tabular}

${ }^{2} 2$ to 5 percent change in one or more output measurements.

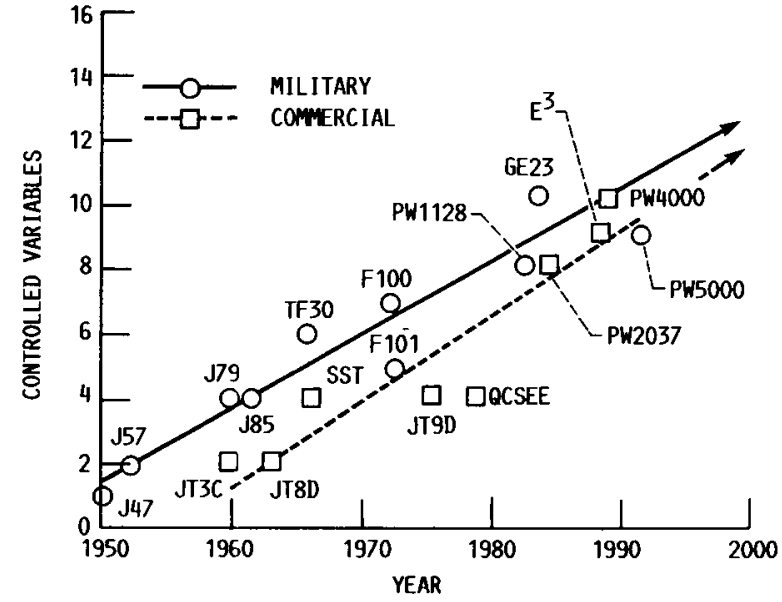

FIGURE 1. - TRENDS IN CONTROL COMPLEXITY OF AIRCRAFT TURBINE ENGINES.

\section{- MEASURED}

EST IMATED
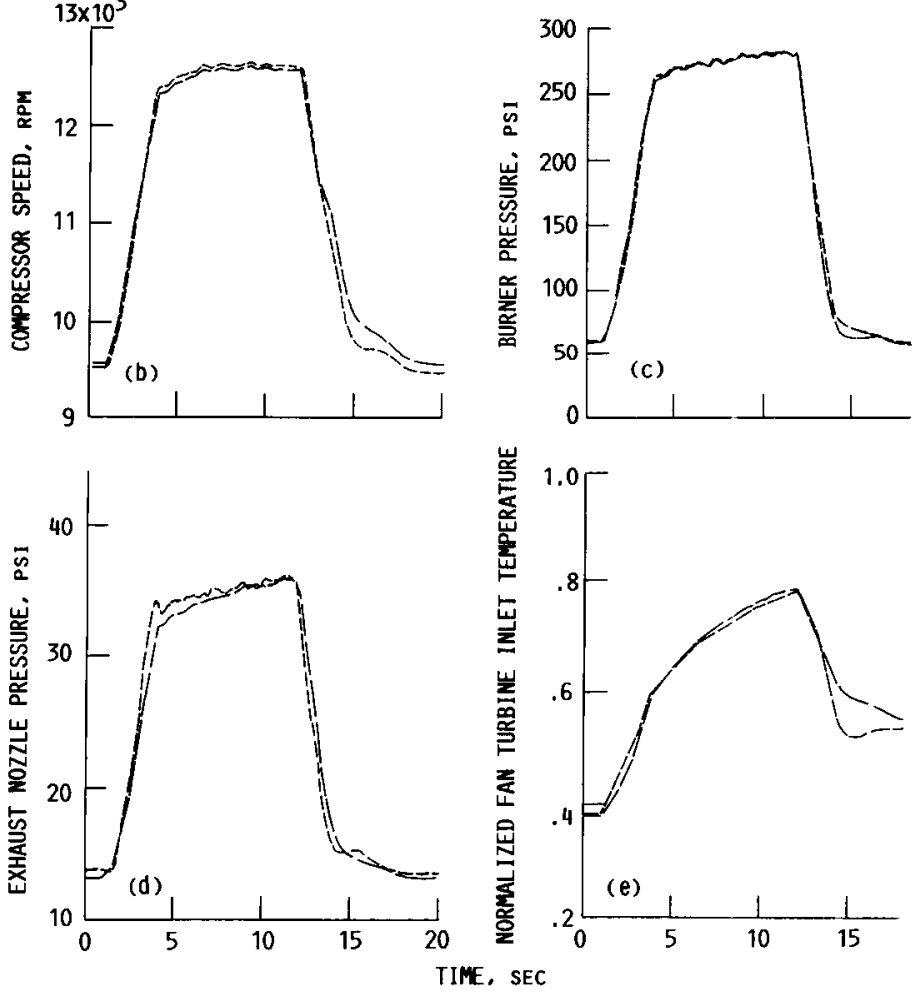

FIGURE 2. - A COMPARISON OF ACCOMMODATION FILTER ESTIMATES WITH ENGINE MEASUREMENTS FOR FIVE ENGINE OUTPUTS. DATA SHOW AN ACCELERATION AND DECELERATION FROM IDLE TO FULL PONER AT 10000 FT ALTITUDE AND MACH NUMBER OF 0.6 .

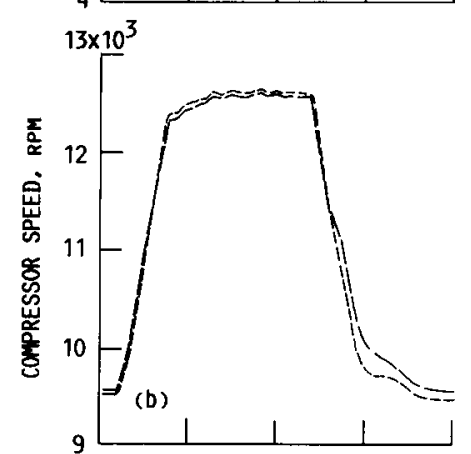




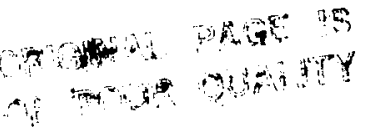

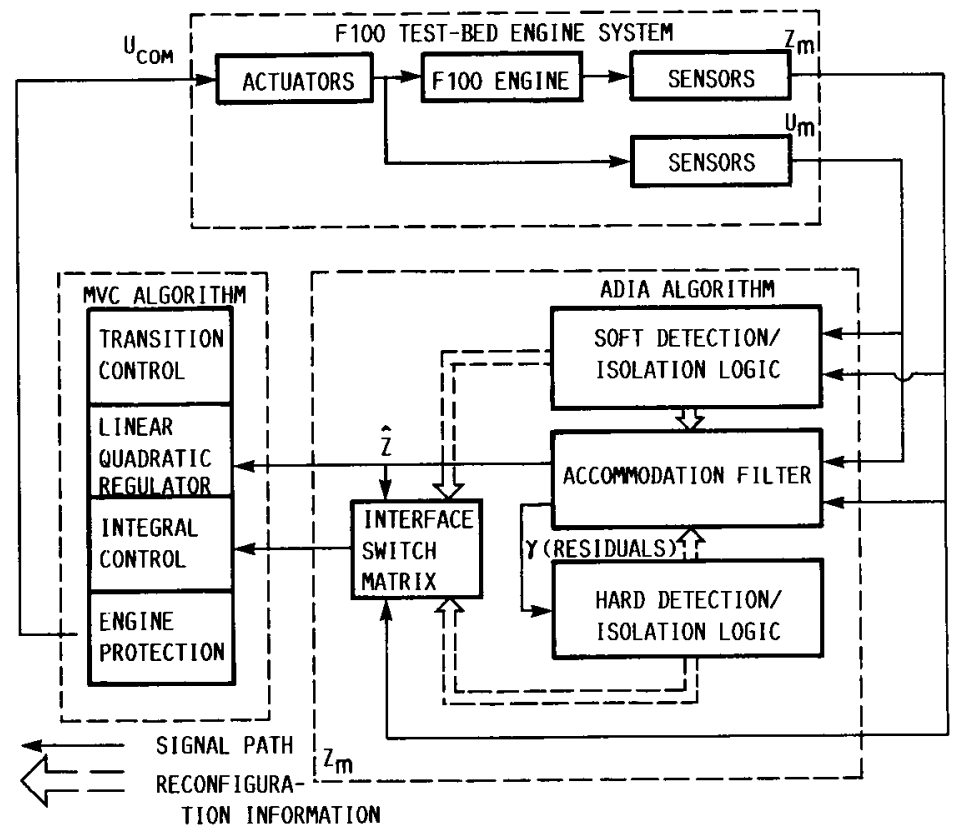

FIGURE 3. - F100 TEST-BED SYSTEM WITH ADIA ALGORITHM AND MVC CONTROL.

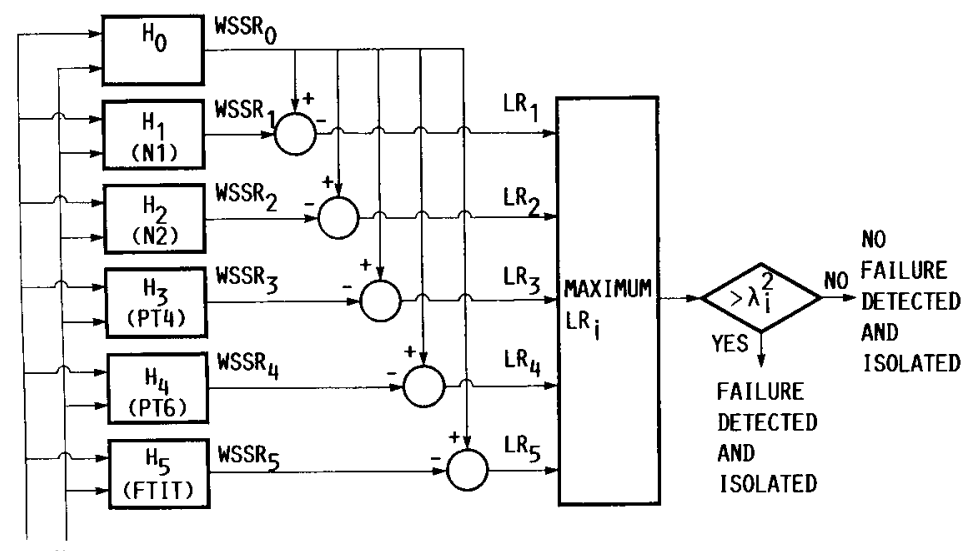

$z_{m} U_{m}$

FIGURE 4. - SOFT FAILURE DETECTION AND ISOLATION LOGIC BLOCK DIAGRAM.

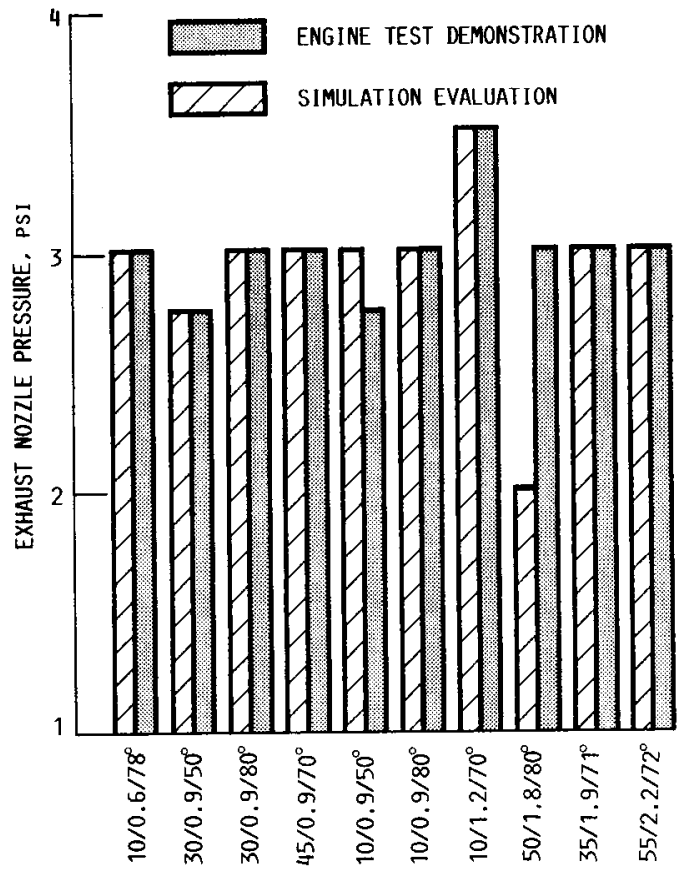

OPERATING POINT, ALTITUDE (1000 FT)/MACH NUMBER/ PILOT'S REQUEST

FIGURE 5. - MINIMUM DETECTABLE MAGNITUDES OF EXHAUST NOZZLE PRESSURE SENSOR, SOFT BIAS FAILURES AT 10 OPERATING POINTS ( 4 SUPERSONIC, 6 SUBSONIC). 


\section{ORIGNAL PAGE IS \\ OF POOR QUALITY}
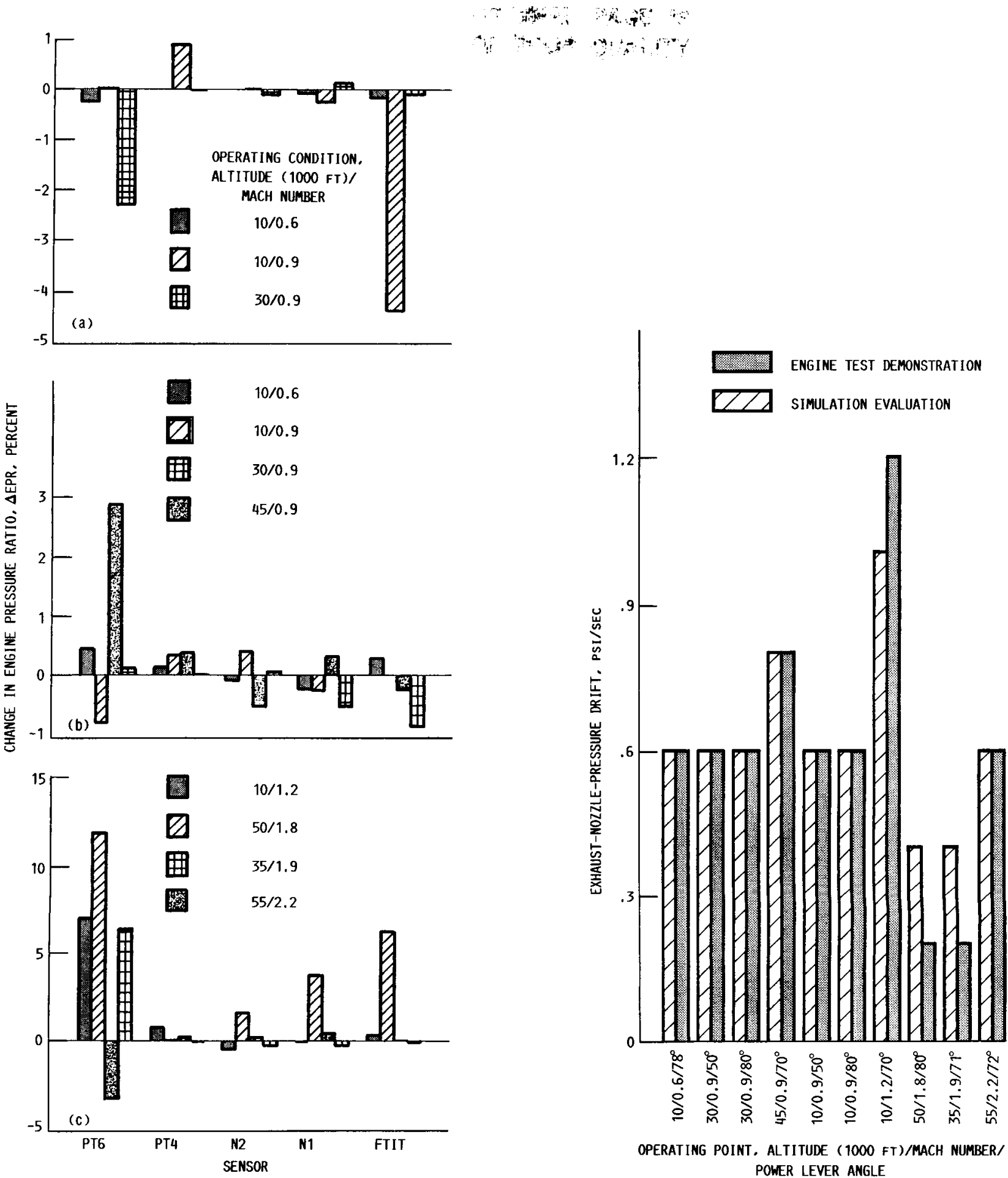

FIGURE 6. - STEADY-STATE ACCOMMODATION PERFORMANCE FOR SOFT BIAS SENSOR FAILURES.

OPERATING POINT, ALTITUDE (1000 FT)/MACH NUMBER/ POWER LEVER ANGLE

FIGURE 7. - MINIMUM DETECTABLE MAGNITUDES OF EXHAUST NOZZLE PRESSURE SENSOR SOFT DRIFT FAILURES AT 10 OPERATING POINTS ( 4 SUPERSONIC, 6 SUBSONIC). 

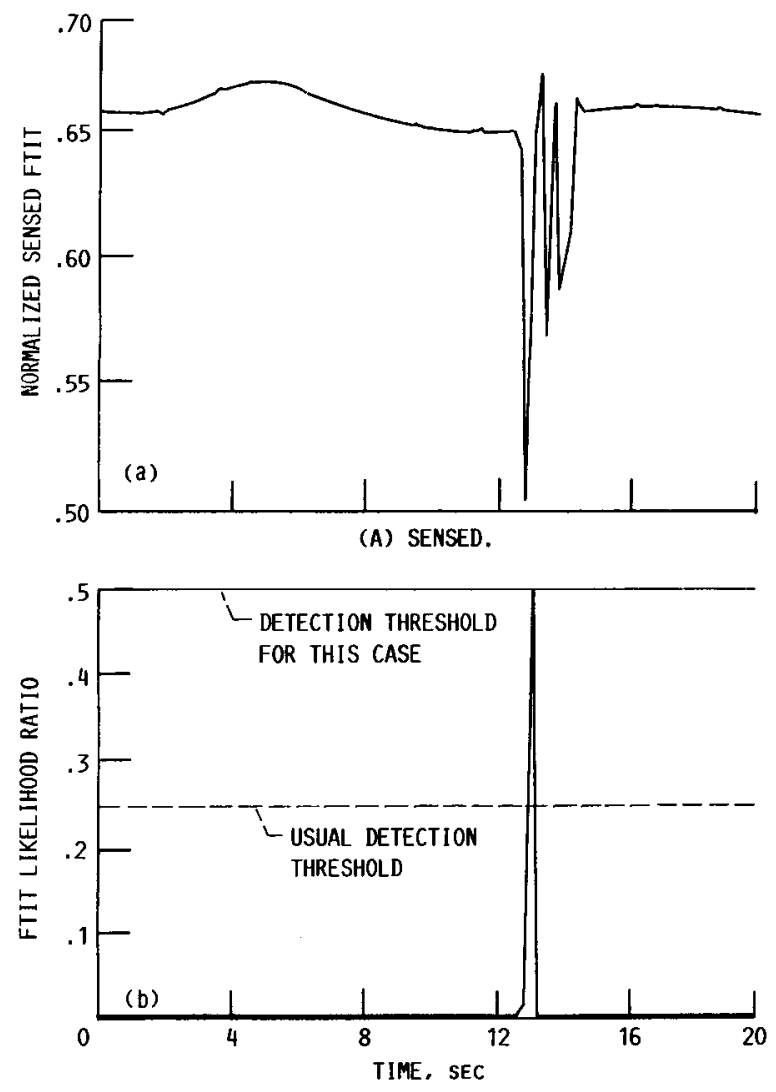

(B) LIKELIHOOD RATIO.

FIGURE 8. - UNPLANNED FTIT MEASUREMENT HARDWARE SOFT FAILURE.
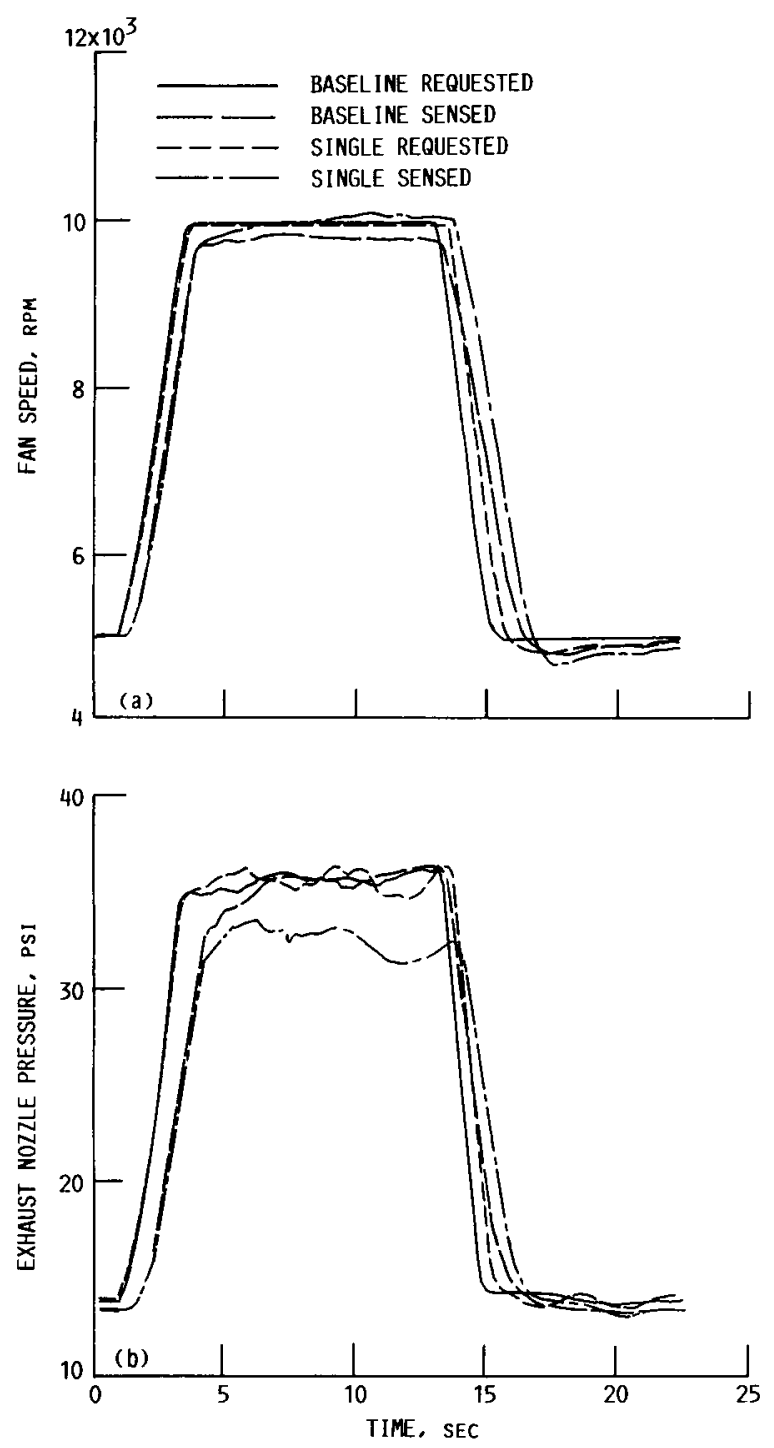

FIGURE 9. - ENGINE ACCLERATION-DECELERATION RESPONSE WITH EXHAUST NOZZLE PRESSURE FAILURE. 


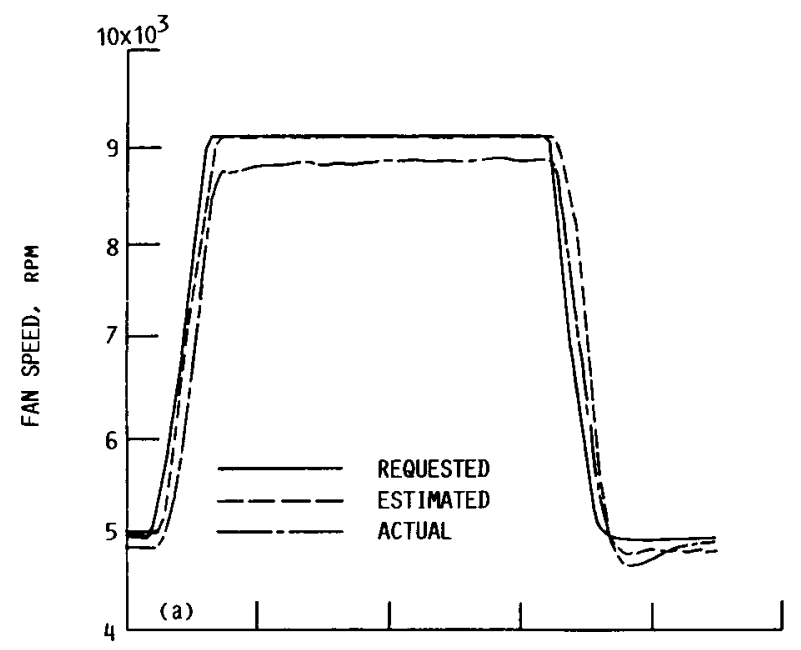

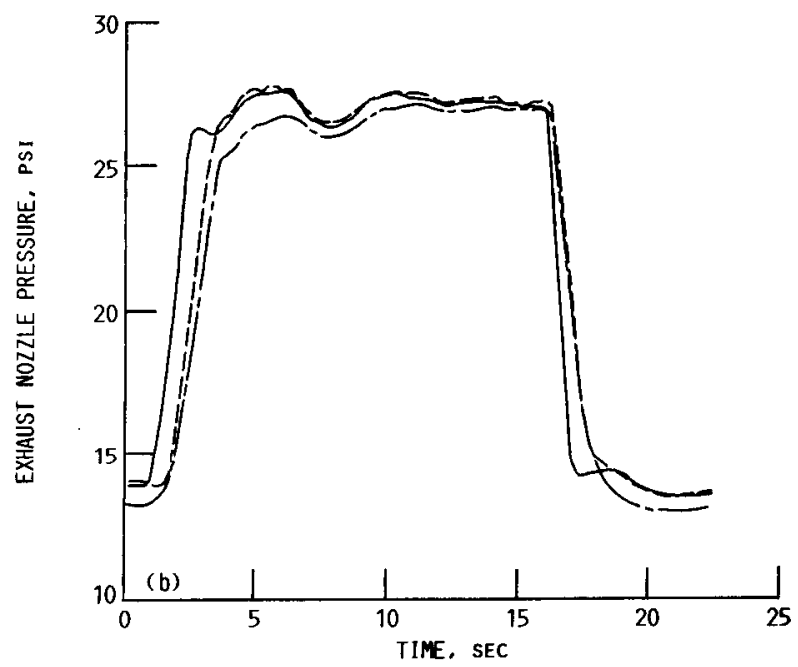

FIGURE 10. - OPEN LOOP ACCELERATION-DECELERATION.
SIEADY STATE \& TRANSIENT

\begin{tabular}{|c|c|c|c|c|c|}
\hline \multirow[t]{2}{*}{ SENSORS } & \multirow{2}{*}{$\begin{array}{c}\text { SINGLE } \\
\text { FAILURE } \\
\text { SLS }\end{array}$} & \multicolumn{3}{|c|}{ DUAL FAILURES } & \multirow{2}{*}{$\begin{array}{c}\text { TRIPLE } \\
\text { FAlLURES } \\
25 \mathrm{~K} / 1.0 \mathrm{M} \\
\end{array}$} \\
\hline & & SLS & $25 \mathrm{~K} / 1.0 \mathrm{M}$ & $35 \mathrm{~K} / 0.8 \mathrm{M}$ & \\
\hline \multicolumn{6}{|l|}{ PS3 } \\
\hline NF & $\bigcirc$ & & $\Delta$ & & \\
\hline$T 56$ & 0 & D & 0 & $\square$ & $\square \square$ \\
\hline$T 25$ & 0 & 0 & $\triangle$ & [ & $\square$ \\
\hline NG & 0 & & $\triangle$ & [ & $\square$ \\
\hline WFM & 0 & & & & \\
\hline
\end{tabular}

$20 \%$ TO 100\% TO 20\% DRY THRUST

30\% TO 100\% TO 30\% DRY THRUST

30\% TO MINIMUM A/B TO 30\% DRY THRUST

$\triangle 30 \%$ TO MAXIMUM A/B TO $30 \%$ DRY THRUST 


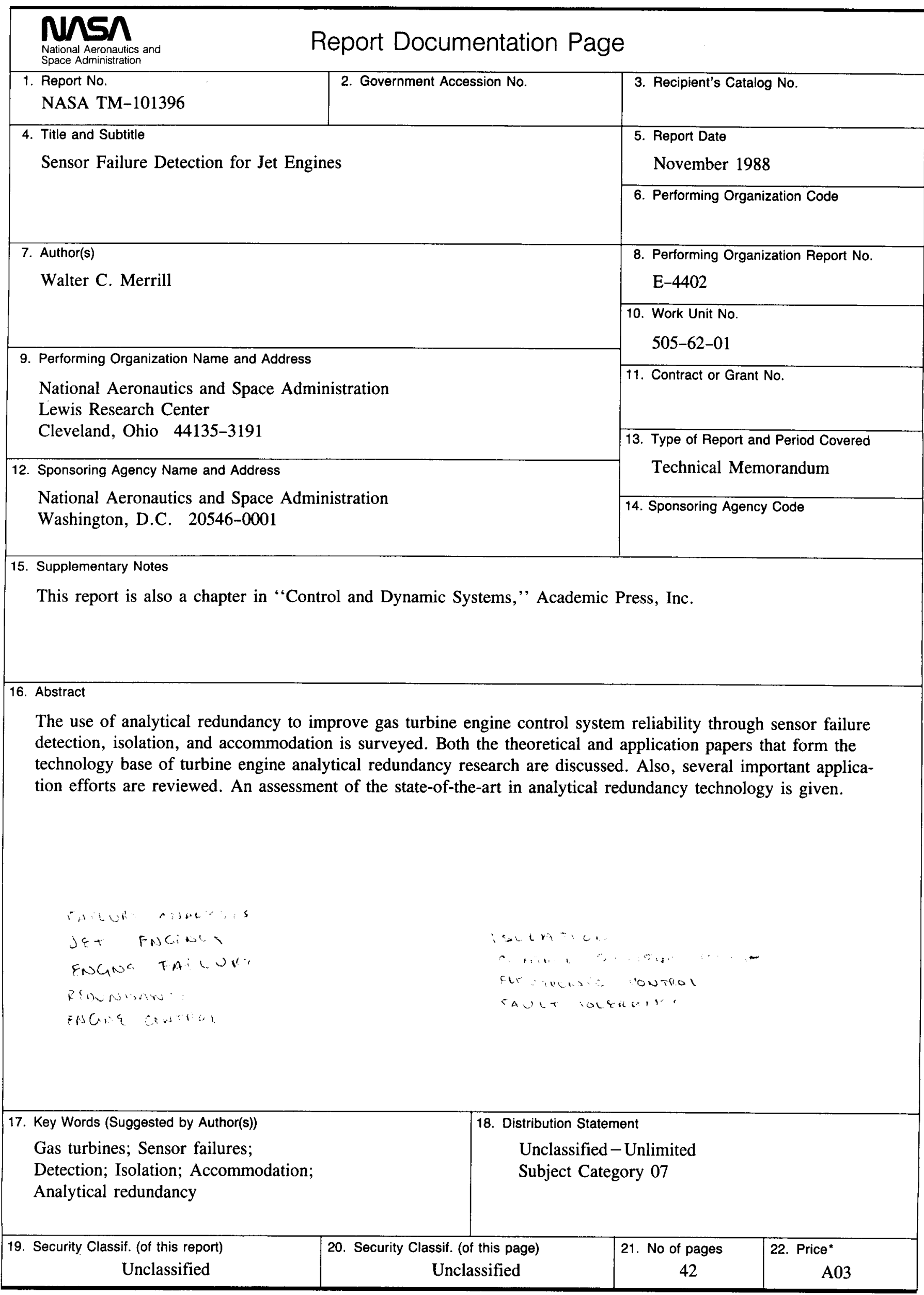


National Aeronautics and

Space Administration

Lewis Research Center

Cleveland, Ohio 44135

\section{Ortictel Businese}

Penelty for Privele Uae $\mathbf{8 0 0}$
FOUATH CLASS MAIL

ADDRESS CORRECTION REQUESTED
|||||

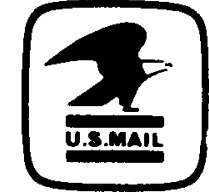

Postage and Fees Paid

Natıonal Aeronautics and

Space Administration

NA'SA 451 